DOI: $10.14451 / 2.126 .54$

\title{
ОЦЕНКА ХОЗЯЙСТВУЮЩИМИ СУБЪЕКТАМИ ИНВЕСТИЦИОННЫХ КАЧЕСТВ ИНСТРУМЕНТОВ РЫНКА ЦЕННЫХ БУМАГ
}

\author{
(c) 2018 Ляченков Юрий Николаевич \\ аспирант \\ Самарский государственный экономический университет \\ 443090, Самара, ул. Советской армии, 141 \\ E-mail:mkonoval@mail.ru
}

В статье рассмотрено инвестиционное поведение хозяйствующих субъектов на рынке ценных бумаг, связанное с вложением денежных средств в различные финансовые инструменты. Обосновывается необходимость диверсификации инвестиционного портфеля экономических агентов в сторону увеличения доли вложений в облигации.

Ключевые слова: хозяйствующие субъекты, инвестиционные качества, инвестиции, фондовый рыHOK

По мере развития фондовых и срочных рынков значение финансовых инструментов в инвестиционной деятельности значительно увеличилось. Как правило, инвестор на рынке ценных бумаг ограничивался одной целью - кратно увеличить свой капитал, получив доход от тех или иных финансовых инструментов. Однако в современных реалиях возможность недополучения дохода или, более того, потеря вложенных денежных средств очевидна в связи с постоянно изменяющимися экономическими условиями. При таких ситуациях инвестору желательно сохранить свои вложенные сбережения на том уровне, который был в самом начале до вложения в финансовые инструменты.

Использование финансовых инструментов сегодня предполагает не только их прямую связь с фактическими и ожидаемыми денежными потоками, но и применяется для установления и передела права собственности. Следовательно, в процессе финансового инвестирования главной задачей потенциального покупателя различных инструментов на рынке ценных бумаг является оценка инвестиционных качеств отдельных финансовых инструментов, обращающихся на рынке.

В ходе осуществления инвестиционной деятельности на рынке ценных бумаг нельзя не рассмотреть понятие финансового инструмента. Финансовый инструмент как экономическая категория возникла в ходе развития элементов рыночной экономики, формирование которой началось в западных странах.

На современном этапе понятие финансового инструмента не ограничивается только исполь-

зованием на рынке ценных бумаг, но включает себя целый спектр механизмов, обусловленных осуществлением финансовой деятельности. Финансовые инструменты постоянно развиваются, что связано, в первую очередь, с появлением их новых видов с различными характеристиками и инвестиционными качествами.

Для более полного изучения понятия «финансовый инструмент» следует рассмотреть эволюцию подходов к его определению. Изначально трактовка данного термина обозначала выделение трех основных категорий финансовых инструментов [11]:

- денежные средства (средства во вкладах, на расчетных счетах и кассе);

- кредитные инструменты (облигации, кредиты, депозиты);

- способы участия в уставном капитале (акции и паи).

По мере появления новых финансовых активов, обязательств и операций с ними, а также с развитием рынков капитала, терминология изменялась. Появилась необходимость в проведении определенной грани между финансовыми инструментами и, собственно, самими финансовыми продуктами (активами или обязательствами), лежащими в основе первых, которыми и происходит манипулирование.

Стоит отметить, что в области финансов в середине 80-х годов двадцатого века большую популярность получило новое направление, получившее название финансового инжиниринга (англ. financial engineering), когда лондонские банкиры начали создавать в своих банках отделы по управлению рисками, а сотрудники этих 
отделов получили должность «финансового инженера». В начале его предназначение сводилось к комплексному описанию финансовых инструментов, однако в ходе появления новых подходов к определению финансового инжиниринга известными учеными (Дж. Маршалл, М. Кьюперт, П. Кудре и др.), сущность данного термина определяла комплексную дисциплину, включающую в себя проектирование и разработку финансовых продуктов, стратегий и системы для удовлетворения потребностей финансовых учреждений, корпораций, правительств и домашних хозяйств.

Далее использование и разработка новых финансовых инструментов в основном сводилась к получению прибыли путём спекулятивной торговли на срочных рынках и рынках капитала, то есть с помощью этих инструментов происходила мобилизация источников финансирования.

Несмотря на обилие научных исследований по финансовым инструментам, наиболее соответствующая современным реалиям трактовка терминологии представлена в международных стандартах финансовой отчетности (МСФО). Важно знать, что в данных стандартах изложены не только общие определения неоднозначно трактуемых финансовых инструментов, активов и обязательств, но и примеры их использования.

Рассматриваемой категории посвящены три стандарта, публикуемые на официальном сайте Минфина РФ: «Финансовые инструменты: раскрытие и представление» (MCФO IAS32), «Финансовые инструменты: признание и оценка» (МСФО IAS39) [7], «Финансовые инструменты: раскрытие информации» (MCФO IFRS7).

Согласно МСФО 32, финансовый инструмент - это договор, в результате которого возникает финансовый актив у одного предприятия и одновременно появляется финансовое обязательство или долевой инструмент у другого.

Исходя из данного понятия, основным элементом финансового инструмента является договор. В статье 420 ГК РФ 5 указано, что договор - это соглашение двух или нескольких лиц об установлении, изменении или прекращении гражданских прав и обязанностей. При заключении договора у всех сторон возникает некое обязательство.

К договорам, лежащих в основе финансовых инструментов, относятся лишь те, в которых происходят изменения в финансовых активах, обязательствах или капитале. Следовательно, данные категории рассматриваются не с точки зрения гражданско-правовой природы, а с экономической. Исходя из официальной информации, предоставленной в МСФО 32, можно рассмотреть особенности каждой категории.

Финансовый актив - актив, представляющий собой:

- денежные средства;

- долевые инструменты другой организации;

- предусмотренное договором право получить денежные средства или иной финансовый актив от другой организации или обменять финансовые активы или обязательства с другой организацией на условиях, потенциально выгодных для последней;

- договор, в котором расчеты будут или могут быть осуществлены с помощью собственных долевых инструментов, которыми могут являться: непроизводные инструменты, с помощью которых организация получает переменное количество своих собственных долевых инструментов; производные инструменты, в которых расчеты регулируются иным способом, отличным от обмена фиксированной суммы денежных средств или иного финансового актива на определенное количество долевых собственных инструментов.

Под финансовым обязательством в МСФО понимается договорное обязательство, согласно которому возникает обязательства по передаче денежных средств или какого-либо иного финансового актива другой организации (например, кредиторская задолженность); по обмену финансовых инструментов с другой организацией на потенциально невыгодных условиях для последней.

Долевой инструмент - это договор, подтверждающий право на остаточную долю в активах организации после вычета всех ее обязательств. Проще говоря, это способ участия в капитале (уставном фонде) хозяйствующего субъекта. Кроме долевых инструментов в инвестиционной деятельности важны долговые финансовые инструменты, имеющие специфические имущественно-правовые последствия как для эмитентов, так и для держателей.

Следовательно, исходя из вышеперечисленного, для определения операции как финансового инструмента, она должна иметь две отличительные характеристики: 
1) в основе данной операции должны лежать финансовые активы или обязательства;

2) операция должна иметь форму договора.

В частности, такие активы, как запасы производства, материальные или нематериальные активы, полученные авансы и т.п. не относятся к финансовым активам даже при том, что владение ими предположительно может привести к притоку денежных средств, однако прав получить некий доход в будущем не возникает.

Отсутствие наличия договорной составляющей в отношениях, возникающих по поводу налоговой задолженности перед государством, также не приводит к формированию финансового инструмента.

Таким образом, сущность финансового инструмента определяется в заключении документарно-оформленного вида обязательства с целью долгосрочного или краткосрочного инвестирования. Данный термин активно используется не только в монографической литературе, но и упоминается в ряде нормативных документов. В частности, это относится к Федеральному закону от 22.04.1996 г. № 39-Ф3 «О рынке ценных бумаг».

Здесь под финансовым инструментом понимается ценная бумага или производный финансовый инструмент.

При принятии решения о приобретении или продаже финансовых инструментов, инвесторам важно определить их инвестиционные качества.

Основными факторами, учитываемыми при оценке инвестиционных качеств ценных бумаг, являются следующие 14: надежность, ликвидность, степень инвестиционного риска и доходность.

Так как инвестирование в финансовые инструменты на рынке ценных бумаг - это заведомо рискованная деятельность, следует понимать, что от принятого инвестором решения зависит его дальнейший финансовый результат.

Оценка рисков и сопоставление его с уровнем будущей доходности позволяет узнать, какие виды финансовых инструментов являются прибыльными при наличии высокого или низкого уровней риска [3].

Исходя из результатов оценки инвестиционных качеств каждого желаемого финансового инструмента, производится решение о его приобретении/продаже. На практике невозможно подобрать такой вид финансового инструмента, который был бы одновременно и самым надежным, и доходным, и ликвидным. То, что не позволяет один финансовый инструмент, может быть достигнуто за счет подбора пакета бумаг с различными свойствами, так называемого портфеля ценных бумаг или инвестиционного портфеля.

Рассматривая вопрос об оценке инвестиционных качеств финансовых инструментов на практике необходимо решить одну существенную проблему: имеются ли сегодня такие инструменты, вкладывая в которые, можно было бы достигнуть поставленных целей его владельца без существенных потерь.

В условиях экономической нестабильности и тенденции к падению курса рубля люди предпочитают использовать привычные для них финансовые инструменты - депозиты, с целью обеспечить сбережение своих вложенных средств. Оценивая привлекательность банковских депозитов для инвестирования, стоит рассмотреть динамику процентных ставок по вкладам физических лиц в рублях 24 и уровня инфляции 25 в России за прошедшие 5 лет (рисунок).

Исходя из данного графика видно, что в течение долгого времени уровень инфляции в стране оставался опережающим по сравнению со ставками по депозитам в Сбербанке. Особенно заметен разрыв во время периода 2014-2015 годов (ставка по депозитам $-8,75 \%$, в то время как уровень инфляции $-12,91 \%)$, когда произошел валютный кризис рубля по причинам снижения мировых цен на нефть и ужесточения антироссийских экономических санкций. В последнее время банки стараются сбалансировать ситуацию, привлекая большие объемы кредитования, однако видна негативная тенденция: процентные ставки ежегодно снижаются (7,4\% в 2014 году против 4,5\% годовых в 2018 г.), что может привести к обесцениванию хранящихся денег граждан. Поэтому для инвесторов, желающих вложить свои средства на длительный период, но при этом получить доходность, превышающую банковскую, будет полезным использовать такой финансовый инструмент, как облигации федерального займа $[1,2]$.

Облигации федерального займа - это долговые ценные бумаги, доступные физическим и юридическим лицам, которые выпускает Правительство Российской Федерации в лице Министерства финансов. 


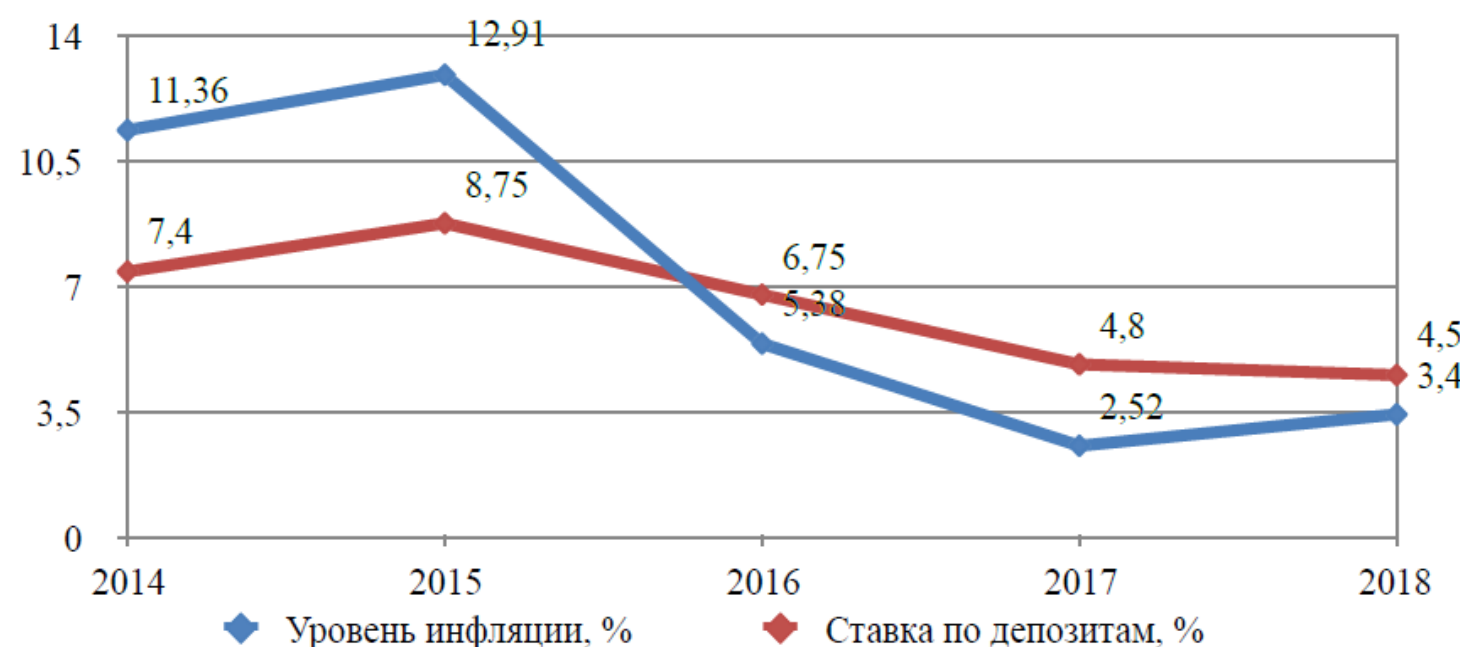

Рис. Сравнительная характеристика уровня инфляции и ставок по депозитам с 2014 по 2018 гг.,\% [8]

На сегодняшний день в обращении находится более 30 разных выпусков ОФЗ, которые имеют различные сроки погашения вплоть до февраля 2036. Кроме сроков и доходности, ОФЗ также имеют различные виды условий по выплате купонов, расчету купонов, расчету номинала и т.д. По срокам обращения ОФЗ могут быть краткосрочными, среднесрочными или долгосрочными. Что касается видов ОФЗ, доступных сегодня, то можно выделить ОФЗ-ПД, ОФЗ-ПК, ОФЗ-АД и ОФЗ-ИН. Рассмотрим их поподробнее.

ОФЗ-ПД - облигации с постоянным доходом. Это означает, что купонные платежи по ним устанавливаются один раз и больше не изменяются. Стоит отметить, что именно таких облигаций на биржевых торгах большинство - 19 выпусков.

ОФЗ-ПК - облигации с переменным купоном. Это означает, что купонные платежи по ним могут изменяться по заранее установленным для каждого выпуска правилам, а после погашения текущего купона в торговом терминале QUIK 7 можно будет наблюдать его новое значение. Размер купона по таким облигациям имеет привязку к ставке RUONIA (Ruble Overnight Index Average - индикативная взвешенная ставка однодневных рублевых кредитов на условиях overnight) в форме её значения плюс фиксированная надбавка. По состоянию на декабрь 2018 года, ее значение установилось на уровне 7,07\%.

ОФЗ-АД - облигации с амортизацией долга. Это означает, что инвестор будет получать купон, а также часть постепенно погашаемого долга по подобным бумагам.

ОФЗ-ИН - это инфляционно-индексиру- емые облигации. Специфика подобных бумаг заключается в том, что помимо купонных платежей происходит ежегодная индексация их номинала. Это означает, что бумага выпускается по 1000 руб., а в дальнейшем к её номиналу ежегодно прибавляется значение инфляции. Таким образом, этот инвестиционный инструмент способен защитить от роста инфляции, однако при её снижении доходность облигаций данного вида тоже уменьшается.

Местом торговли ОФЗ является ПАО «Московская биржа» и приобрести их может абсолютно любой человек. Главный атрибут инвестора ОФЗ - это наличие либо брокерского счета, либо индивидуального инвестиционного счета, без которых никак нельзя играть на рынке ценных бумаг.

На бирже так же можно рассчитать доходность или цену любой приглянувшейся ОФЗ. Достаточно выбрать интересующий инструмент, дату расчета показателей и сравнить ценовые и доходные показатели.

Для сравнения привлекательности различных видов доступных на сегодня ОФЗ, рассмотрим следующие имеющиеся выпуски (табл.).

Исходя из текущей ситуации на рынке гособлигаций ОФЗ, наиболее привлекательной в плане доходности (8,7\% годовых) считается ОФЗ-ПД. Однако стоит понимать, что при более высокой дюрации (т.е. волатильности цены облигации при изменении процентных ставок в экономике), есть риски недополучить вложенные деньги. При снижении ключевой ставки доходность ОФЗ-ПД может оказаться весьма интересной, о чём говорит и тот факт, что выпуски облигаций 
Таблица. Котировки ОФЗ на Московской бирже [4,5]

\begin{tabular}{|c|c|c|c|c|c|c|c|}
\hline ОФЗ & Вид ОФЗ & $\begin{array}{c}\text { Лет до } \\
\text { погашения }\end{array}$ & $\begin{array}{l}\text { Цена,\% от } \\
\text { номинала }\end{array}$ & $\begin{array}{c}\text { Доход- } \\
\text { ность,\% }\end{array}$ & Купон, руб. & НКД, руб. & $\begin{array}{c}\text { Дюрация, } \\
\text { лет }\end{array}$ \\
\hline $\begin{array}{r}\text { ОФЗ } \\
26225\end{array}$ & Пд & 15,4 & 89,395 & 8,7 & 36,15 & 22,08 & 9,1 \\
\hline $\begin{array}{c}\text { ОФЗ } \\
29006\end{array}$ & ПК & 6,09 & 103,057 & 7,8 & 41,14 & 34,58 & 4,78 \\
\hline $\begin{array}{c}\text { ОФЗ } \\
46020\end{array}$ & АД & 17,15 & 85,55 & 8,7 & 34,41 & 27,6 & 9,25 \\
\hline $\begin{array}{c}\text { ОФЗ } \\
52002\end{array}$ & ИН & 9,1 & 93,597 & 3,4 & 12,84 & 10,28 & 8,08 \\
\hline
\end{tabular}

в 2017 году сопровождались повышенным спросом инвесторов, в разы превысив предложение. Объем рынка ОФЗ в целом вырос на $17,9 \%$ и составил около 6,72531 трлн. руб [6].

Наименьшей дюрацией обладает ОФЗ с переменным купоном. Её доходность меньше на 0,9\%, чем у ОФЗ-ПД и ОФЗ-АД, однако выплата купона и НКД значительно выше значений предыдущих видов.

Соответственно, при повышении процентных ставок, цена таких облигаций подешевеет в меньшей степени, чем ОФЗ-ПД. Если инвестору потребуется зафиксировать доходность выше депозита - следует уделить внимание ОФЗПК. Дальнейшее изменение доходности ОФЗПК напрямую связано с изменчивостью ставки RUONIA [9].

Согласно данным предыдущего графика, доходность по ОФЗ-ИН эквивалентна текущей инфляции в 2018 году. Однако при дальнейшем снижении уровня инфляции в стране покупать ОФЗ-ИН не стоит: индексируемый номинал будет падать вслед за снижающейся инфляцией, а выплата по купону не так высока, как у других видов (12,84 руб.) [9].

При анализе привлекательности ОФЗ следует отметить появление нового инструмента, ОФЗ-Н. ОФЗ-Н 32 - это государственные облигации, выпущенные сроком на три года специально для населения (народные). Доходность новых госбумаг, если держать их до погашения, превысит среднюю доходность по депозитам, а также остальных видов ОФЗ. Если на сегодняшний день средняя доходность по ОФЗ находится на уровне приблизительно 8,2\% годовых, то доходность «народных» ОФЗ составит 8,7\% годовых, что более чем вдвое превышает уровень прогнозируемой инфляции в 4\% в год. Значит, инвестиции в «народные» ОФЗ это также хорошая альтернатива банковским депозитам. Таким образом, ОФЗ-Н представляют интерес для физических лиц и способны диверсифицировать портфель, предоставляя доходность, гарантированную государством.

Таким образом, исходя из проведенного анализа, можно сделать вывод о том, что ОФЗ - это надежный способ вложения капитала для людей и компаний России, не желающих рисковать и спекулятивно получать доход, а желающих с максимальной надежностью сохранить свои свободные денежные средства в среднесрочной перспективе.

Следует выделить следующие достоинства ОФЗ по сравнению с другими финансовыми инструментами:

Во-первых, облигации Министерства финансов считаются более надежными, чем вложение средств в банковские депозиты. Если инвестор размещает сумму большую той, по которой агентство по страхованию вкладов РФ гарантирует возврат (а это 1,4 млн. рублей 34 по закону «О страховании вкладов физических лиц в банках РФ») в облигации государства, то существует возможность получения гарантированного дохода, как и по депозитным вкладам.

Во-вторых, выбор в сторону ОФЗ возможен, если инвестор не доверяет банкам, хоть сумма его вклада и не превышает установленный лимит страхования вкладов или в том случае, если его не устраивает ставка по депозиту, предлагаемого банком. Сегодня можно самостоятельно (или же с помощью услуг профессионального участника рынка ценных бумаг) подобрать облигации с приличной доходностью. 
В-третьих, инвестор может использовать ОФЗ для дополнительной диверсификации рисков при наличии у него достаточно большого инвестиционного портфеля.

B-четвертых, облигации полезны тем, кто хочет вложить свои деньги на долгий срок, но не приемлет высокий риск.
В сравнении с банковскими депозитами облигации - более гибкий, хотя и более сложный инструмент. Поэтому перед приобретением стоит предварительно изучить текущую ситуацию на рынке ОФЗ и принять правильное для себя решение.

\section{Библиографический список}

1. Абдрахимова 3.Р., Корвякова Е.Н. Облигации федерального займа как инструмент инвестирования в экономику для населения //Вестник ИЭАУ. 2017. № . 15. С. 1.

2. Боровский В. Н., Новикова И. С. Государственные облигации Российской Федерации //Science Time. 2016. № . 12. С. 70.

3. Бородина О.В., Захарова А.Ю. Инвестиционные качества ценных бумаг //Вопросы науки и образования. 2017. № . 6. С. 62-64.

4. Ермак А., Гапон Ю. Рынок рублевых облигаций: заоблачный спрос 2017 года // БК Регион [Электронный pecypc] - URL: http://bonds.finam.ru/comments/item/bk-region-rynok-rublevyx-obligaciiy-zaoblachnyiyspros-2017-goda/ (дата обращения: 24.11.2018)

5. Картаоходности ОФЗ - котировки гособлигаций ОФЗ/ Московская биржа MOEX - [Электронный ресурс] URL: https://smart-lab.ru/q/ofz/ (дата обращения: 30.12.2018)

6. Коряковцев В. Облигации федерального займа. Москва. 2017. С. 34-39.

7. Международный стандарт финансовой отчетности (IAS) 39 «Финансовые инструменты: признание и оценка» // Информация официального сайта Министерства финансов Российской Федерации - [Электронный ресурс] - URL: https://www.minfin.ru/ru/search/?q_4=ias+39\&source_id_4=6\#ixzz5 WXti9n3E (дата обращения: 12.11.2018)

8. Мильчакова Н. «Народные» ОФЗ: плюсы и минусы для инвесторов// - banki.ru - [Электронный ресурс] URL: http://www.banki.ru/news/columnists/?id=9726056 (дата обращения: 24.11.2018)

9. Расчет доходности/цены долговых инструментов/ Московская биржа MOEX - [Электронный ресурс] - URL: https://www.moex.com/ru/bondization/calc (дата обращения: 30.12.2018)

10. Ставка RUONIA (Ruble Overnight Index Average) / База данных ЦБ РФ - [Электронный ресурс] - URL: https:// www.cbr.ru/hd_base/ruonia/ (дата обращения: 30.12.2018)

11. Ajupov A.A. et al. Economic bases of formation and development of financial engineering in financial innovation //Mediterranean Journal of Social Sciences. 2014. T. 5. № . 24. C. 148. 